\title{
Effectiveness of Different Insoles on Plantar Pressure Distribution using Finite Element Simulation
}

\author{
Rezchell Chame Alysion, Solehuddin Shuib, Nur Faiqa Ismail
}

\begin{abstract}
Finite Element to investigate different insole was developed to predict insole behavioral when pressure is applied onto the insole surface. Insole is a shoe insert that provides a cushion and support to human body so that it relieves foot pain and readjust human bone structure into correct posture. People who are suffering foot pain such as foot ulcer and foot deformities were caused by physical activity like walking and running. $F E$ simulation are the best clinical tools used to investigate the effectiveness of the insole before fabricate. The major factors that affect the effectiveness of insoles are the type of material and the thickness based on the shape of insole. Only few of researchers had studied material and the thickness but none of them were studied the basic insole which is flat insole that almost commonly use in our daily life. Thus, this research is to investigate which is the best effective flat insole with different material and thickness by using Finite Element (FE), which using ANSYS Workbench V19.2 for analysis purpose. This research focused on post processing result which are Equivalent (von Mises) Stress, Shear Stress and Deformation. This research requires one male person weighs $64 \mathrm{~kg}$ to investigate the maximum pressure contact between foot and Plantar-Pressure Distribution (F-Scan) which is TekscanTM. Based from F-scan data, it has been found that the highest pressure occurs at calcaneus (heel part) which recorded 192KPa. The F-Scan result data has transferred into ANSYS Workbench V19.2 simulation Analysis for investigation. Based on the FE Analysis, it can be concluded that Polyurethane with $5 \mathrm{~mm}$ thick flat insole is the most effective insole among all types of insoles.
\end{abstract}

Keywords : Finite Element Analysis, F-scan, Insole

\section{INTRODUCTION}

Insole or shoe insert, otherwise known as foot orthosis has been used to relief pain and reduce the risks of injuries from any human's movement or physical activity. It also helps to relieve foot disorder such as cerebral palsy. Cerebral palsy is a foot disorder that limits the movement and posture of an individual's body [1]. According to Malaysia's health statistic, Bih-Hwa Ching [2] found that one-third of children with $\mathrm{CP}$ from overall Malaysia population. In addition, $\mathrm{Dr}$

Revised Manuscript Received on November 19, 2019

Rezchell Chame Alysion, Faculty of Mechanical Engineering, Universiti Teknologi MARA, Shah Alam, Selangor, Malaysia. Email: raychame95@gmail.com

Solehuddin Shuib*, Faculty of Mechanical Engineering, Universiti Teknologi MARA, Shah Alam, Selangor, Malaysia. Email: solehuddin2455@uitm.edu.my

Nur Faiqa Ismail, Faculty of Mechanical Engineering, Universiti Teknologi MARA, Shah Alam, Selangor, Malaysia. Email: nfaiqa.ismail@gmail.com

Hasniza reported that the overall prevalence of diabetes

mellitus (DM) among Malaysians was 22.9\% in year 2013, and $12.1 \%$ [3] of them were newly diagnosed diabetics. The patient who suffered DM will have potential lead to Diabetic foot in which is defined by foot ulceration that associated with neuropathy and/or peripheral arterial disease of a lower limb in a patient with diabetes. It has been reported that foot disease had contributed to $12 \%$ of all diabetic admission in Malaysia. Therefore insole effectively plays an important role not just to relieve discomfort but to alleviate pain such as foot disease as to enhancing clinical performance [4]. The major that affects the effectiveness of insole is the material, thickness and types of shape [5]. There were a wide scope of studies carried out during investigate the effectiveness of different insoles. In general, recent studies can be categorized by several factors which including Plantar Pressure used, size of an insoles, Material and post processing from FE final simulation result. The objectives of this finding is to investigate the highest point pressure contact on F-scan. Besides, it also to identify the location which indicates highest of pressure on the F-Scan. In addition, it is vital to investigate the post processing of the different materials such as EVMS, Deformation and Shear Stress. Last but not least, by comparing the result, it will able to determine the most effective insole among all of their types with different thickness and materials. This finding required TekscanTM as a plantar pressure machine used to record the measurement of ground contact faces that can be used to assess the loads to which the human body is subjected in normal activities, like walking, or in more demanding situations such as in sports [6]. One of devices that use to record data is using sensor pad. It has thin sensor thickness by $0.2 \mathrm{~mm}$ and a large number of one layer as shown in Fig. 1.

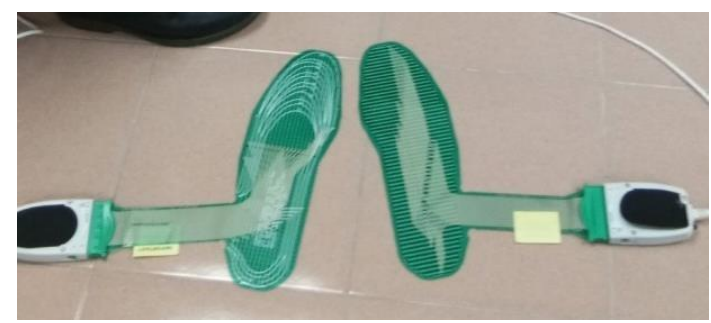

Fig. 1. A set of sensor pad use to detect pressure when foot is contact onto it 


\section{Effectiveness of Different Insoles on Plantar Pressure Distribution using Finite Element Simulation}

Other researchers such as Glaudius [7] and Dumitras [8] has conducted the same comparison of insole's material behavior on a specific shoe which called as 'rigid rocker bottom' therapeutic shoe design. Therefore, this study using Flat Insole design as no other researchers had done with this design. This flat insole is currently using with the size of 11 UK size in which use as a daily life such as walking and running. The materials that commonly used to produce insole are Ethylene-Vinyl Acetate (EVA), Polyester, Polyurethane and Silicon Rubber. Table-I shows the mechanical properties for the he EVA, Polyester, Polyurethane, and Silicon Rubber.

Table-I: Mechanical properties of the insole material

\begin{tabular}{|c|c|c|}
\hline Material & $\begin{array}{c}\text { Modulus of } \\
\text { Elasticity, E } \\
\text { (MPa) }\end{array}$ & $\begin{array}{c}\text { Poisson Ratio, } \\
\mathbf{v}\end{array}$ \\
\hline $\begin{array}{c}\text { Ethylene-Vinyl } \\
\text { Acetate (EVA) [9] }\end{array}$ & 33 & 0.35 \\
\hline Polyester [10] & 2,100 & 0.26 \\
\hline $\begin{array}{c}\text { Polyurethane } \\
\text { Foam [11] }\end{array}$ & 44.5 & 0.40 \\
\hline $\begin{array}{c}\text { Silicon Rubber } \\
\text { [13] }\end{array}$ & 130,000 & 0.27 \\
\hline
\end{tabular}

Ethylene-Vinyl Acetate (EVA) is an elasometric polymer that produces flexibility with good clarity and gloss, low temperature toughness, stress- crack residence, and resistance to UV radiation. Polyester is a category of polymers that contain the ester group in their main chain through polymerization. Polyurethane is a copolymer that absorbs shock and able to withstand higher loads [9]-[10]. Silicon Rubber is a copolymers that contain more than two polymers which improves strength and durability of the insoles.

Finite element (FE) modeling of foot and footwear offers a unique computational tool, as it is allowing multiple insole design variables to be assessed in a controlled and efficient manner than traditional experiments [11]-[14]. In this study, the insole was developed by using a commercial CAD Software known as CATIA V5 meanwhile ANSYS Workbench V19.2 was used for FE simulation. Four post processing to evaluate and record the comparison of different insole such as Equivalent von Mises Stress, Deformation and Shear Stress. Equivalent von Mises stress is used to determine the ability of yielding the stress is applied on the material. If EVMS is higher than ultimate yielding stress, thus it tend to be deform plastically. The equation of von Mises is shown in (1).

$$
\begin{gathered}
\sigma^{s}=\frac{1}{\sqrt{2}}\left[\left(\sigma_{1}-\sigma_{2}\right)^{2}+\left(\sigma_{2}-\sigma_{3}\right)^{2}+\left(\sigma_{3}-\sigma_{1}\right)^{2}\right]^{\frac{1}{2}} \\
\sigma_{1}>\sigma_{2}>\sigma_{3}
\end{gathered}
$$

Where $\sigma^{\prime}$ is von mises stress and $\sigma_{1}, \sigma_{2}$ and $\sigma_{3}$ is a normal stress acting on a plane $\mathrm{x}, \mathrm{y}$ and $\mathrm{z}$ in three dimensional respectively.

Deformation refers to any changes of length due to force applied on the material. The higher the deformation will tends to fracture but at the same time it also provide good cushioning rather than lower deformation. The equation of deformation is shown in (2).

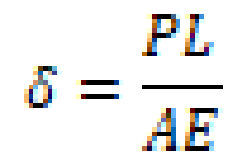

Where $\mathrm{P}, \mathrm{L}, \mathrm{A}$, and $\mathrm{E}$ is Force $(\mathrm{N})$, Original length (m), Cross sectional Area $\left(\mathrm{m}^{2}\right)$ and Young Modulus (GPa), respectively. Shear stress is a stress that acting parallel on the surface of the body. The lower the stress, if the shear stress is higher than ultimate yielding stress, thus it will undergo plastic deformation. Shear stress can be constructed if there are minimum stress and maximum stress via Mohr's Circle. The shear stress can be found in the Mohr's Circle as illustrated in Fig. 2.

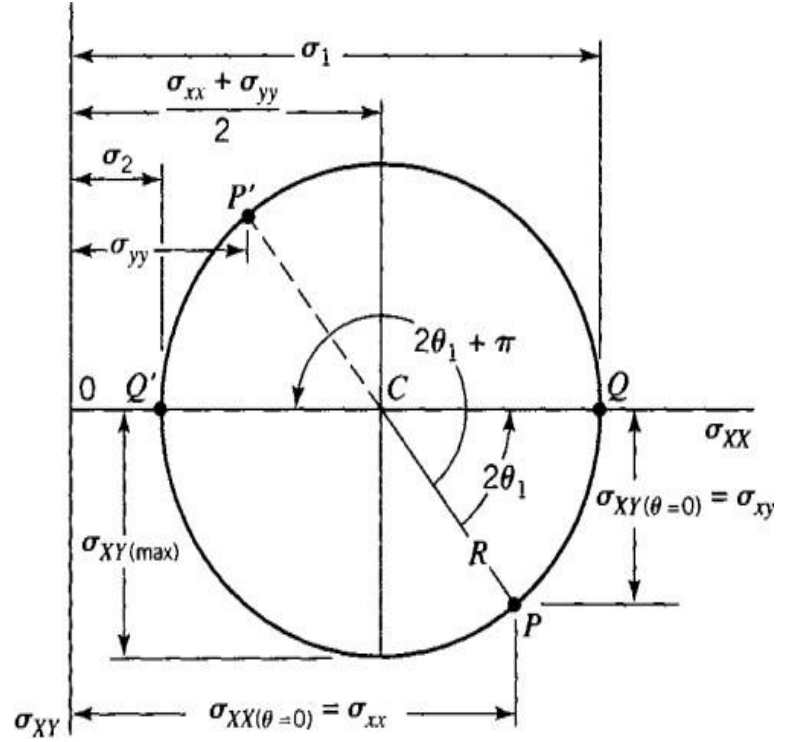

Fig. 2. A Mohr's Circle used to find maximum shear stress Despite all researchers has investigated the most effective insoles of different material and thickness, but there is only limited specific types of shape insole had been done. However, none of the researchers had done comparison of our daily basis of insole which also known as 'Flat insole'. The obtained knowledge of this study is to investigate the behavioral of flat insole with different materials and thickness when foot pressure is applied. Despite it is basic foot orthosis need in our life, it is vital to determine in which type material and thickness is the best suitable for flat insole.

\section{MATERIALS AND METHOD}

A Plantar Pressure distribution or known as F-scan was installed to record human foot pressure prior interpret into FE simulation. Fig. 3 shows the plantar pressure machine used which is TekscanTM in order to analyze pressure field when foot is contact on the sensory layer of plantar. The F-scan was calibrated prior starting to analyze the foot. The result F-scan will show the maximum pressure and its location of the foot contact. 


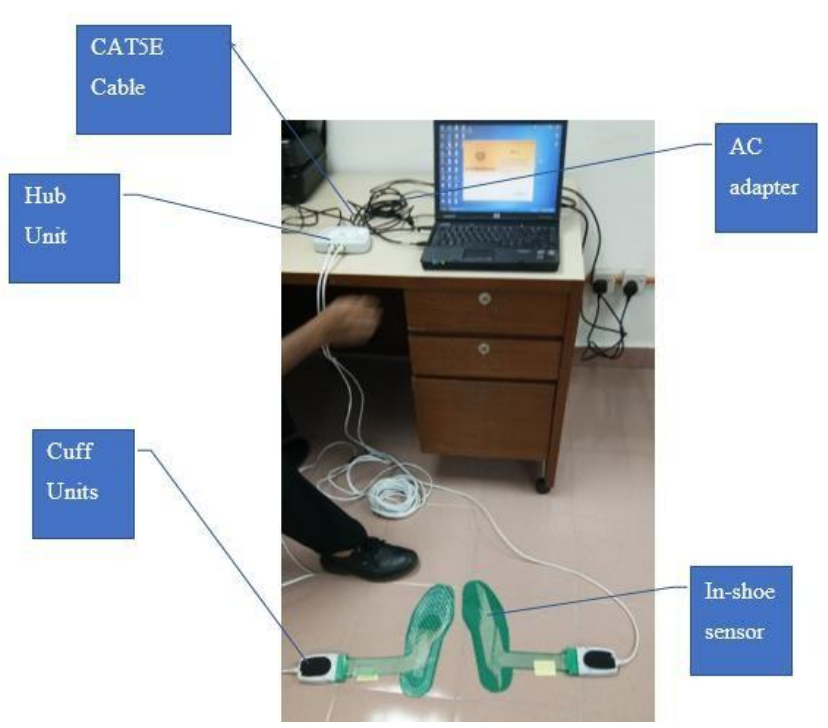

Fig. 3. The installation of F-scan

This F-scan experiment require one subject to be tested. A subject is known age 24 years old, male gender, normal foot arch and no foot deformities were recorded. The subject is standing and balancing for 10 second to optimize the constant foot contact area by spreading both arms. The subject is tested as shown in Fig. 4.

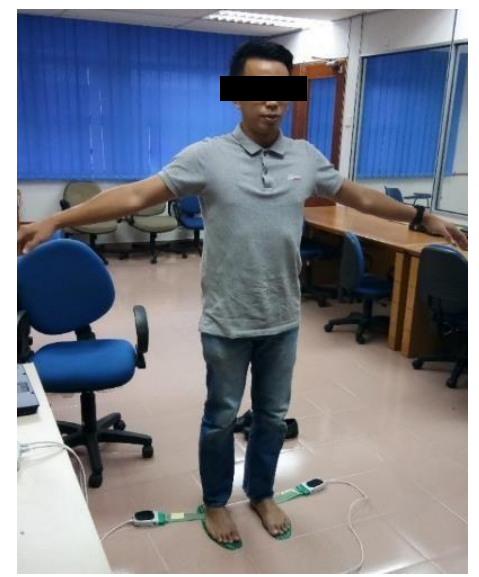

Fig. 4. A subject is on standing position with spreading both arms to increase balancing

The results obtained was taken for FE simulation which done by ANSYS Workbench V19.2 which consider as loading condition. The boundary conditions that meet the post processing result are by thickness, material and meshing. Three different insole design with different thickness $(5 \mathrm{~mm}$, $7 \mathrm{~mm}$ and $9 \mathrm{~mm}$ ) was constructed using CATIA V5 software. Next, the designs was imported into ANSYS Workbench V19.2. Fig. 5 shows the generated insole model. The insole models was then assigned into four materials which are EVA, Polyester, Polyurethane, Silicon Rubber as the material properties shown in Table 1. Next, the mesh of the insole models was created by $5 \mathrm{~mm}$ and $7 \mathrm{~mm}$ at foot contact and non-foot contact respectively as shown in Fig. 6(a). Next, the variable boundary and loading condition of the model was assigned which the loading is based on the F-scan result obtained earlier (refer Fig. 6(b)). There are 12 different insoles (four materials in three different thickness) was analyzed by using FE method. Lastly, the solver information was created to provide post processing information such as von Mises, shear stress and deformation.

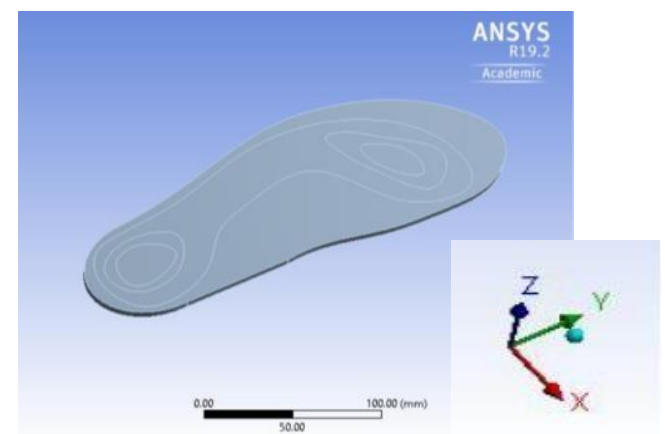

Fig. 5. Flat insole model generated into ANSYS Workbench V19.5

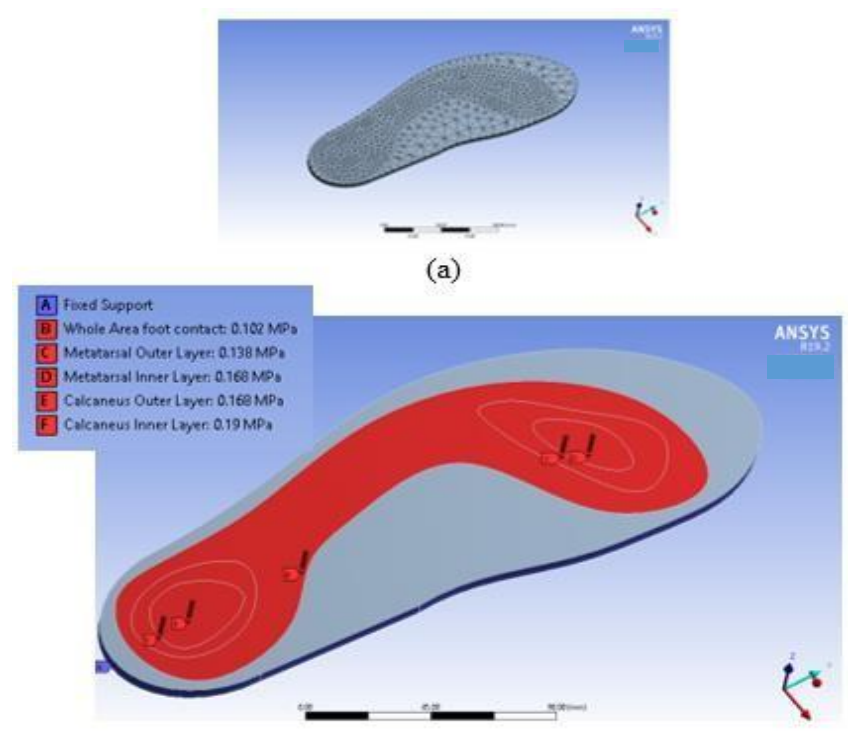

(b)

Fig. 6. (a) Meshing of the insole (b) Loading and boundary condition of the insole

\section{RESULTS AND DISCUSSION}

Fig. 7 shows the maximum pressure of foot recorded by F-scan and the location of peak pressure by single subject during balanced standing.

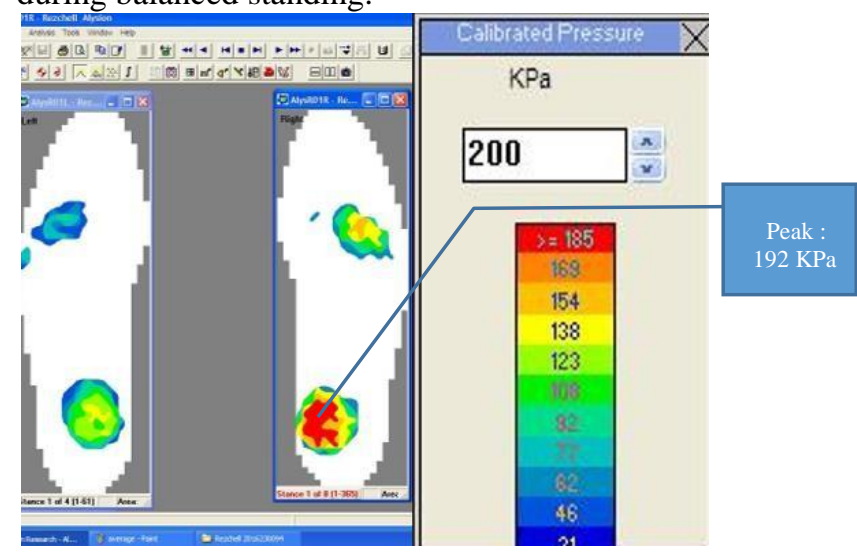

Fig. 7. The pressure distribution from F-scan measurements from a subject during barefoot standing

\section{Published By:}

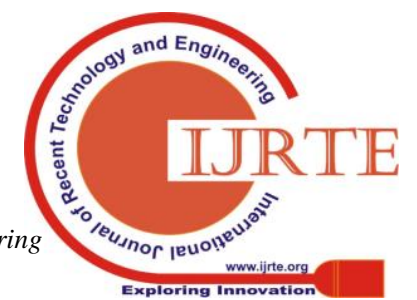




\section{Effectiveness of Different Insoles on Plantar Pressure Distribution using Finite Element Simulation}

As shown in Fig. 7, the highest pressure occurred at calcaneus. Calcaneus has small area of contact compared to metatarsal which gives much higher pressure. Therefore, calcaneus holds the most important foot parts as it hold much pressure rather than other part of human foot. All 12 different types of insoles with different materials and thickness was gathered for observation and comparison. For validation purpose, the current research work was compared with other research work done by Glaudius [7]. Glaudius has investigated the experimental of EVA insole into therapeutic shoes. All the thickness used are same material as Glaudius work. Based on the validation result, it was cleared that $5 \mathrm{~mm}$ thickness have almost similarity with percentage different by $8.73 \%$ whereas for $7 \mathrm{~mm}$ and $9 \mathrm{~mm}$ has similarity by $12.31 \%$ and $19.64 \%$ respectively. The data of the validation compared to Glaudius [7] are presented in Fig.8.

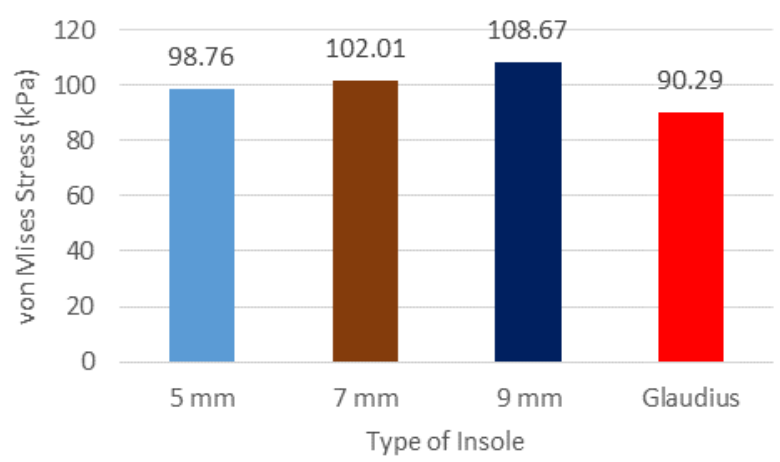

Fig. 8. Validation results based on other research work [4]

In order to find which the best insole for $5 \mathrm{~mm}$, the comparison between materials was made based on the post processing results (von Mises stress, shear stress and deformation). Fig. 9 shows the relationship between von Mises stress and insole material. It can be seen from the data in Fig. 9 that Polyurethane (PU) recorded the lowest value $(80.48 \mathrm{kPa})$ of von Mises stress compared to other materials. The highest von Mises stress for the material was polyester with value of $132 \mathrm{kPa}$. The higher von Mises stress will tends to more yielding after repetitive load in a period of time. Therefore, the best insoles will refer to the lowest possible of von Mises stress.

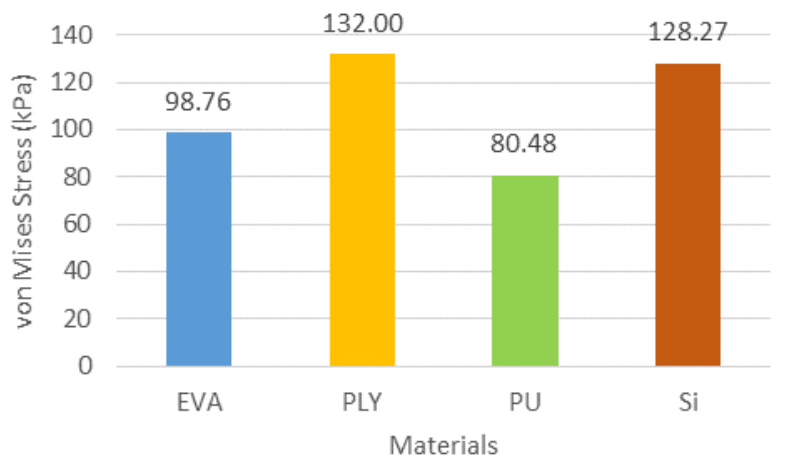

Fig. 9. The von Mises stress result on different materials for $5 \mathrm{~mm}$ thickness

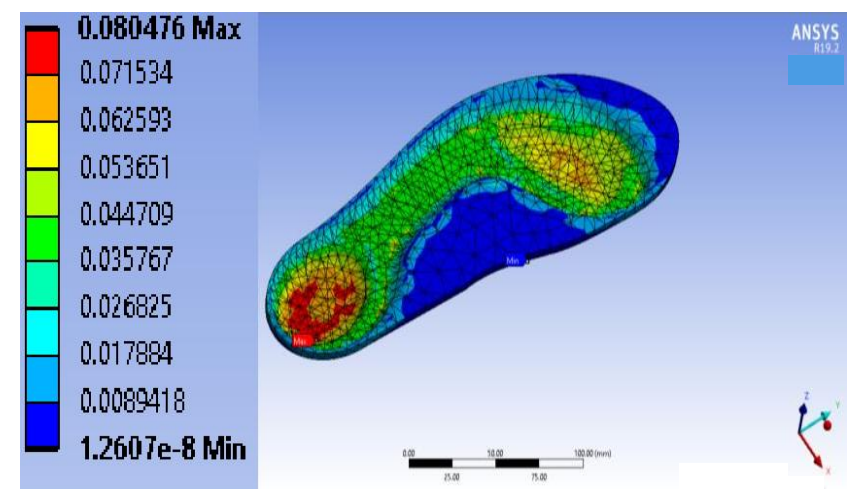

Fig. 10. The von Mises stress distribution of Polyurethane (in MPa) in FE final simulation

Fig. 11 presents the result of directional deformation for different insole material. As shown in the Fig.11, the highest directional deformation occurred at negative z-direction which deform towards below of the insoles. Meanwhile, the highest directional deformation occurred at EVA by $18.5 \mu \mathrm{m}$ in the negative $\mathrm{z}$-direction followed by PU which recorded at $10.69 \mu \mathrm{m}$ in the same direction. The least directional deformation occurred at $-0.00829 \mu \mathrm{m}$ at Silicon Rubber in the same directions too. The best insole will based on the lowest deformation which will gave wider contact area and more reduction of pressure [15]. Although EVA is better in deformation than any other material, this material did not satisfy the other parameter such as shear stress and von Mises stress. PU material shows that it satisfied all three main post processing results. Thus, PU material was chosen as the best insoles as it satisfy all aspects of parameters. The distribution of deformation in Z-direction of PU in FE simulation (see in Fig. 12) shows the inversed result which deformations are vector quantities, meaning it has both magnitude and directions. The minimum shows blue region represent the direction of deformation that goes down providing negative sign with respect to $\mathrm{z}$-axis. Meanwhile for the red region shows the positive sign of deformation with respect to $\mathrm{z}$-axis.

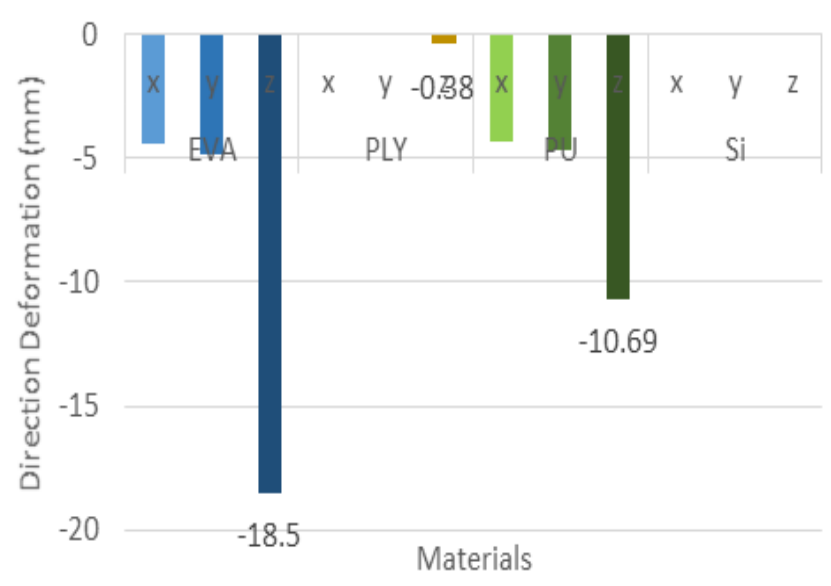

Fig. 11. Directional Deformation for $5 \mathrm{~mm}$ thickness 


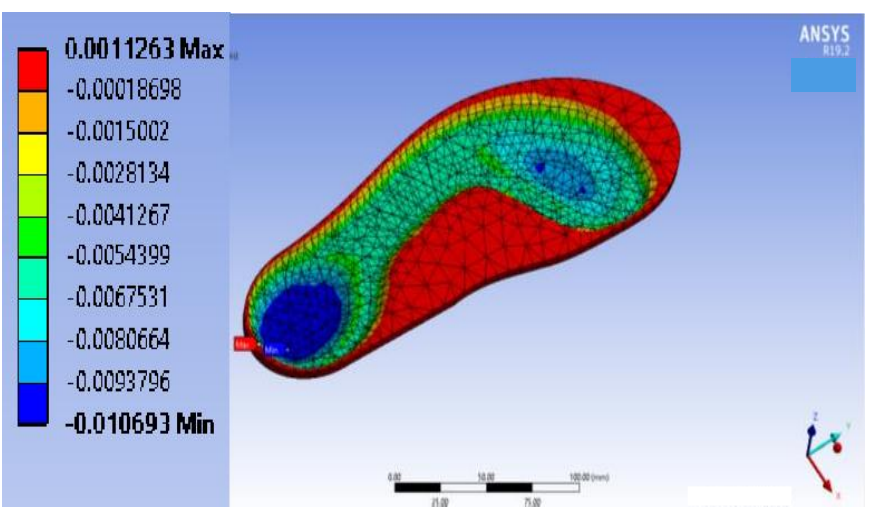

Fig. 12. The distribution of deformation in Z-direction (in mm) of PU material

Fig. 13 shows the max shear stress result on different materials. Based on the result obtained, Polyester (PLY) material recorded the maximum shear stress with value of $66.72 \mathrm{kPa}$, followed by Silicon Rubber (Si), EVA and Polyurethane (PU) by $65.30 \mathrm{kPa}, 50.12 \mathrm{kPa}$, and $40.97 \mathrm{kPa}$, respectively. The value of peak shear stress will causing worn out and resulting pain for people with foot ulcers. Hence, the best insole was based on the lowest shear stress value which is Polyurethane. Fig. 14 shows the maximum shear stress distribution on Polyurethane material. It can be seen that the Polyurethane has less maximum shear stress region (see red region) compared to other insoles material which the maximum shear stress are mainly occurs at calcaneus for all materials.

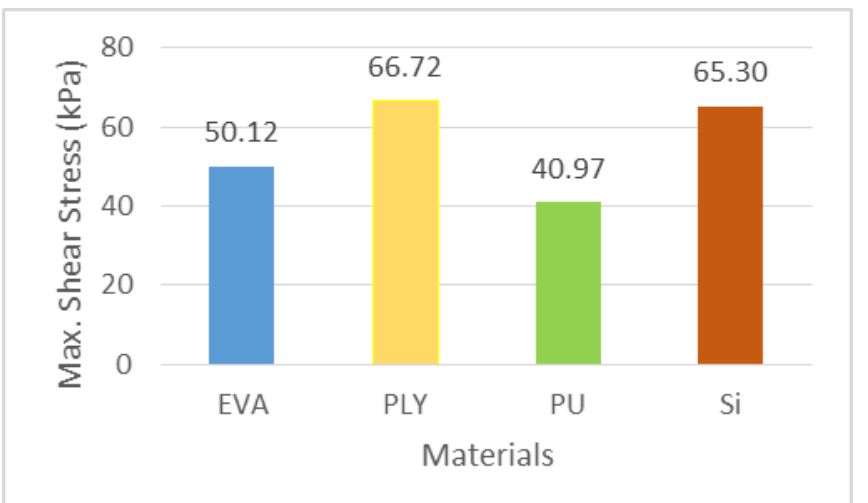

Fig. 13. Maximum shear stress on different insole material

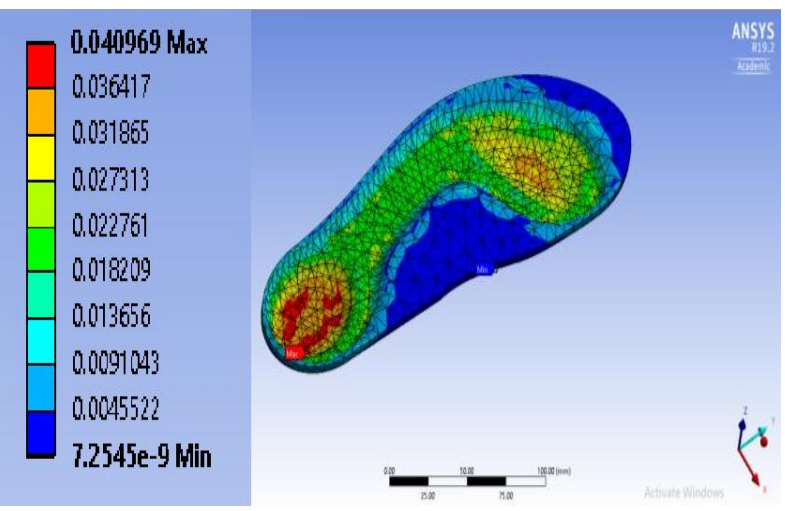

Fig. 14. The contour shows the maximum shear stress of PU (in MPa) in FE Simulation

\section{CONCLUSION}

A finite-element investigation of insoles was developed to investigate the differences insoles on Plantar Pressure Distribution. Plantar. Pressure distribution holds important aspects as it records human pressure in various types of foot and thus giving much accurate and precise for the clinical tool. Based on the findings, it was found that polyurethane with $5 \mathrm{~mm}$ thickness is the most effective among all 12 different types of insoles because it has the lowest value of von Mises stress and shear stress. Thus, polyurethane with thickness $5 \mathrm{~mm}$ was selected as the best insole.

\section{ACKNOWLEDGMENT}

This research was supported by Universiti Teknologi MARA, UiTM and Ministry of Education, Malaysia under Grant No. 600-IRMI 5/3/GIP (056/2019).

\section{REFERENCES}

1. M. Journal, P. H. Medicine, S. Kamaralzaman, P. Division, and P. Minister, "The Economic Burden Of Families Of Children With Cerebral Palsy In Article In Malaysian Journal Of Public Health Medicine ," Malaysian J. Public Heal. Med., no. April, pp. 156-165, 2018.

2. B. H. Ching and T. B. Khoo, "Prevalence and predictive factors of hip displacement in children with cerebral palsy at paediatric institute, Kuala Lumpur hospital," Neurol. Asia, vol. 22, no. 3, pp. 243-252, 2017

3. C. A. Abbott et al., "The North-West Diabetes Foot Care Study: Incidence of, and risk factors for, new diabetic foot ulceration in a community-based patient cohort," Diabet. Med., vol. 19, no. 5, pp. 377-384, 2002.

4. K. Nakajima et al., "Addition of an arch support improves the biomechanical effect of a laterally wedged insole," Gait Posture, vol. 29 no. 2, pp. 208-213, 2009.

5. W.-M. Chen, S.-J. Lee, P. Vee, and S. Lee, "Plantar pressure relief under the metatarsal heads - Therapeutic insole design using threedimensional finite element model of the foot," J. Biomech., vol. 48, pp. 659-665, 2015 .

6. D. Rosenbaum and H. P. Becker, "Plantar pressure distribution measurements. Technical background and clinical applications," Foo and Ankle Surgery, vol. 3, no. 1. pp. 1-14, 1997.

7. G. Lewis, "Finite element analysis of a model of a therapeutic shoe: effect of material selection for the outsole" Biomed. Mater. Eng., vol 13, no. 1, pp. 75-81, 2003.

8. C. G. Dumitras and A. Mihai, "A finite element analysis of a 3-D model of a special footwear," in Annals of DAAAM and Proceedings of the International DAAAM Symposium, 2007.

9. N. Z. Tomić et al., "A rapid test to measure adhesion between optical fibers and ethylene-vinyl acetate copolymer (EVA)," Int. J. Adhes Adhes., vol. 68, pp. 341-350, Jul. 2016.

10. T. Munikenche Gowda, A. C. B. Naidu, and R. Chhaya, "Some mechanical properties of untreated jute fabric-reinforced polyester composites," Compos. Part a Appl. Sci. Manuf., vol. 30, no. 3, pp 277-284, 1999.

11. Y. Lu, L. Tighzert, P. Dole, and D. Erre, "Preparation and properties of starch thermoplastics modified with waterborne polyurethane from renewable resources," Polymer, vol. 46, no. 23, pp. 9863-9870, 2005.

12. D. P. Bakker, F. M. Huijs, J. De Vries, J. W. Klijnstra, H. J. Busscher, and H. C. Van Der Mei, "Bacterial deposition to fluoridated and non-fluoridated polyurethane coatings with different elastic modulus and surface tension in a parallel plate and a stagnation point flow chamber," Colloids Surfaces B Biointerfaces, vol. 32, no. 3, pp. 179-190, 2003

13. D. Y. Khang, H. Jiang, Y. Huang, and J. A. Rogers, “A stretchable form of single-crystal silicon for high-performance electronics on rubber subtrates," Science (80-.). vol. 311, no. 5758, pp. 208-212, 2006.

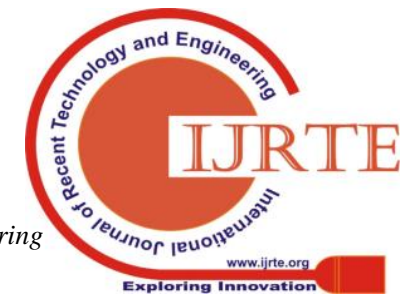




\section{Effectiveness of Different Insoles on Plantar Pressure Distribution using Finite Element Simulation}

14. G. Durmuş and P. Oyar, "Effects of post core materials on stress distribution in the restoration of mandibular second premolars: A finite element analysis," J. Prosthet. Dent., vol. 112, no. 3, pp. 547-554, 2014.

15. J. Tak, M. Cheung, M. Zhang, and J. Club, "A 3-Dimensional Finite Element Model of the Human Foot and Ankle for Insole Design," Arch Phys Med Rehabil, vol. 86, 2005.

\section{AUTHORS PROFILE}

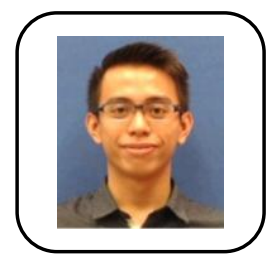

Rezchell Chame Alysion, obtained his Bachelor Degree in Mechanical Engineering from Universiti Teknologi MARA (UiTM). His study involved Mechanical Design, FEA and Insole.

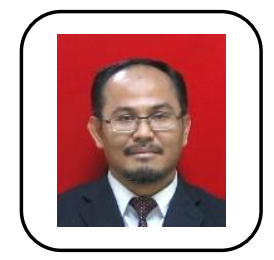

Solehuddin Shuib obtained his Bachelor Degree in Mechanical Engineering from University of Alabama-Birmingham, USA, Master of Mechanical Engineering from University of Toledo, Ohio, USA, and Doctor of Engineering from Universiti Putra Malaysia (UPM), Malaysia. He is an Associate Professor and a member of Biomechanical and Clinical Engineering (BioMeC) Group, at Universiti Teknologi MARA, Malaysia. His research interest includes Mechanical Design, FEA, biomechanics and medical devices.

Nur Faiqa Ismail obtained her Bachelor Degree in Mechanical Engineering from Universiti Teknologi MARA (UiTM). She is currently doing her PhD in Mechanical Engineering at Universiti Teknologi MARA (UiTM). Her study involved Mechanical Design, FEA and polymer composite for biomedical application. 